\section{PRECAUTIONS AGAINST CHEMICAL WARFARE}

\section{War Gases}

Their Identification and Decontamination. By Dr. Morris B. Jacobs. Pp. xiii +180 . (New York : Interscience Publishers, Inc.; London: Imperia Book Co., Ltd., 1942.) 3 dollars.

\section{Gas Warfare}

A Monograph for Instructors. Compiled by W. K. Fitch. Pp. 103. (London: Pharmaceutical Press, 1942.) 2s. $6 d$.

CHEMICAL weapons of war differ from other $\mathcal{C}$ weapons in the degree to which it is possible for a well-prepared nation to protect itself against them. Probably the main reason why they have not yet been used in this War is that the Axis Powers know that our preparations for this form of walfare are very good. An important part of these preparations is the widespread dissemination of knowledge of the subject.

"War Gases", by Morris B. Jacobs, is an up-todate review of the subject from the point of view of a chemist. It deals with all the important gases used in the War of 1914-18 and a few which were not. The physiological effect of each is briefly described, and estimates of its toxicity are quoted from various sources. In this section the concentrations are sometimes given as percentages, sometimes as parts per million and sometimes as milligrams per litre. It would be much easier to compare one gas with another, and one author with another, if concentrations were always given in milligrams per cubic metre. These units are small enough to avoid zeros following decimal points in most cases, and can be applied equally well to true gases, particulate smokes, and mixtures.

The main part of the book is devoted to details of the methods of taking samples of various materials without being poisoned, and of the methods of analysing them for war gases. The gas is placed in one of eight groups, or sub-groups, according to the presence or absence of hydrogen, sulphur, nitrogen, or arsenic, and tests for the individual compounds are then applied. The effects of war gases on materials of various kinds, and methods of decontamination, are discussed in some detail.

"Gas Warfare", by W. K. Fitch, covers a wider and more practical field. As editor of the Pharmaceutical Journal, the author is skilled in the presentation of data in a form which is likely to be attractive to those who have a scientific background, and as a member of the Home Guard he is supremely interested in practical applications. He has summarized the information published in the official handbooks and in larger text-books and presented it in a convenient and practical form. He discusses the history and properties of all the important gases, the weapons in which they are used, their detection and identification and questions of treatment and decontamination. He discusses the theory and detailed use of respirators, their efficiency and even the dermatitis which they may sometimes cause. He describes experiments on gas-proof rooms and methods of training, including the use of preparations which simulate the toxic materials without the danger. He devotes a chapter to the care of animals and gives a reasonably complete bibliography.

It is remarkable how much detailed information has been packed into this small book.

\section{HISTORY OF SCIENCE}

\section{Studies in the History of Science}

By E. A. Speiser, Otto E. Neugebauer, Hermann Ranke, Henry E. Sigerist, Richard H. Shryock, Evarts A. Graham, Edgar A. Singer, Hermann Weyl. (University of Pennsylvania : Bicentennial Conference.) Pp. v+123. (Philadelphia: University of Pennsylvania Press : London : Oxford University Press, 1941.) 9s. 6d. net.

7 HIS book consists of eight lectures on the hisference of the University of Pennsylvania. They are all of absorbing interest, although appealing severally to specialists and not to the general student.

The first lecture, dealing with Mesopotamia in the fourth millennium B.C., discusses the invention in ancient Sumer of what may be called writing. The records throw light on classificatory zoology, botany, geology and chemistry, and translations of them were made from Sumerian into Elamite, Hittite and other languages. The cylinder seal, the immediate ancestor of Mesopotamian writing, was, says Prof. E. A. Speiser, "first and foremost the Sumerian's mark of ownership". So the origin of writing was economic, and the result of a social order based on the recognition of personal rights. There is a marked contrast here with the civilization of Egypt, based on the supreme authority of the Pharaohs. The Egyptian script, perhaps borrowed from Mesopotamia, seems to present differences corresponding to the different cultures of these centres of civilization.

Prof. O. Neugebauer, in a lecture on fundamental concepts in ancient astronomy, discusses the determination of the hour as a unit of time and the way in which ancient astronomers dealt with the difficulty caused by the variable length of the day.

The next lecture has some interesting remarks about the two Egyptian medical papyri, the Ebers Papyrus and the Edwin Smith Papyrus. The former, a collection of recipes, was translated into English in 1937 by Dr. B. Ebbell, a Norwegian ; the second, a surgical treatise, was published with translation and commentary by J. H. Breasted in 1930. The greater part of both is truly scientific, although here and there a piece of folk-medicine or superstition has been interpolated from far inferior sources.

Medieval medicine is discussed in an illuminating way by Prof. H. E. Sigerist. He shows how Arabs and Christians dealt with the problems raised by the adoption of an alien medical system that was only half understood, and finally achieved a medicine of their own by a process of assimilation and synthesis, followed by the revolt that accompanied the Renaissance.

The next two lectures, by Prof. R. H. Shryock and Prof. E. A. Graham respectively, deal with the birth of modern medicine and surgery during the last two hundred years. Medicine grew up with an increased attention paid to etiology rather than to syndromes; surgery depended upon attention to asepsis, anæsthetics and the avoidance of surgical shock. It is an old story, but the summaries here given are models of condensation, with many original observations scattered here and there.

The medical lectures are followed by Prof. E. A. Singer's exposition of what he calls a "logico-historical study of mechanism, vitalism, naturalism". When opposing schools of thought (for example, the mechanical view and the view that admits purpose in Nature) cannot settle their differences by experi- 